\title{
Virtual Screening and Biochemical Testing of Borocycles as Immunoproteasome Inhibitors
}

\author{
Levente Kollár ${ }^{1}$, György Gábor Ferenczyํㅜ, Matic Proj², Martina Gobec², Stanislav Gobec², \\ Izidor Sosič̌2, György Miklós Keserü1*

\footnotetext{
1 Medicinal Chemistry Research Group, Research Centre for Natural Sciences, H-1117 Budapest, 2 Magyar tudósok krt., Hungary

2 Faculty of Pharmacy, University of Ljubljana, SI-1000 Ljubljana, 7 Aškerčeva cesta, Slovenia

*Corresponding author, e-mail: keseru.gyorgy@ttk.hu
}

Received: 16 September 2020, Accepted: 20 November 2020, Published online: 31 May 2021

\begin{abstract}
Inhibition of the immunoproteasome (iCP) offers new opportunities in the treatment of cancer, autoimmune disorders and neurodegenerative diseases. Inspired by the success of boronic acids as proteasome inhibitors we have complied a virtual library of commercially available 5- and 6-membered borocycles and performed a structure based virtual screening against the chymotrypsinlike $(\beta 5 \mathrm{i})$ subunit of the iCP. The top scored docking poses were visually inspected to select compounds for experimental testing. Six compounds with 5-membered ring and another six compounds with 6-membered ring were subjected to biochemical tests. All compounds exhibited detectable inhibitory activity at $100 \mu \mathrm{M}$ concentration and these are the first reported cyclic boronic acid inhibitors of the iCP. Structural variations including the ring size and the substitution of the borocyles and the substitution pattern of the attached aromatic ring resulted in no major variation of the inhibitory activity. We propose that the evaluation of larger cycling boronic acid libraries is needed to fully elucidate the potential of these structures.
\end{abstract}

Keywords

immunoproteasome, virtual screening, biochemical testing, borocycles

\section{Introduction}

The proteasome is a multiprotein complex which has multicatalytic properties. It assists in the degradation of damaged proteins into short peptide sequences and represents the crucial part of the ubiquitin-proteasome system [1-4]. It has proven to be a valuable pharmacological target for the treatment of various disorders such as cancer, inflammation and immune diseases $[5,6]$.

The proteasome can be divided into two parts: the $19 \mathrm{~S}$ regulatory particle (19S RP) and the $20 \mathrm{~S}$ catalytic core particle (20S CP). The latter consists of four heptameric rings, two internal $\beta$-rings and two external $\alpha$-rings. Three $\beta$-rings are responsible for the catalytic activities, which are executed by the $\beta 1$ (caspase-like), the $\beta 2$ (trypsin-like), and the $\beta 5$ (chymotrypsin-like) subunits [1-4].

The immunoproteasome (iCP) is an isoform of the $20 \mathrm{~S}$ CP. It is expressed in response to a viral infection or after stimulation by pro-inflammatory cytokines, such as interferon $\gamma$ [3]. In the immunoproteasome, $\beta 1 \mathrm{i}, \beta 2 \mathrm{i}$ and $\beta 5 \mathrm{i}$ subunits are incorporated into internal $\beta$-ring instead of constitutive subunits. Selective inhibition of the iCP offers new opportunities in the treatment of inflammation and autoimmune diseases, hematologic malignancies and in several neurological diseases, where neuroinflammation is a hallmark of disease progression [3, 6]. Several inhibitors of the iCP were reported to date; however, of the majority have peptidic structures, which result in poor pharmacokinetic properties in most of the cases. Another notable issue is the limited selectivity against the CP $[1,6]$.

Despite that boronic acids are known in chemical literature since the $19^{\text {th }}$ century, growing interest towards these structures can be witnessed in the last few decades [7]. Not only they act as important reagents in synthetic chemistry (Suzuki-coupling [8], Chan-Lam coupling [9], Petasis reaction [10], etc.), different kinds of boronic acids have been subject to intensive research in medicinal chemistry [11].

Boronic acid-based inhibitors have been reported for several enzymes. These are predominantly, but not exclusive, serine proteases, and the covalent binding to the catalytic serine residue has been proved or can be hypothesized [12]. Nowadays, significant efforts are devoted to the 
design, synthesis and screening of boronic acid libraries. Dozens of hits against various targets were identified and a few drug discovery projects resulted in FDA-approved drugs (Table 1). For further insights into this topic, the reader is referred to excellent reviews focusing on boronic acids in medicinal chemistry [7, 11].

A large number of boronic acids have been investigated as $\mathrm{CP}$ and $\mathrm{iCP}$ inhibitors and bortezomib (Table 1) has been approved by FDA for the treatment of multiple myeloma. Inspired by the success of boronic acids as immunoproteasome inhibitors we have initiated a hit finding campaign with the objective of discovering cyclic boronic acids as inhibitors of the $\beta 5 \mathrm{i}$ subunit of iCP. This type of compounds is well known by medicinal chemists, and three cyclic boronic acid drugs have been approved by the FDA recently (Table 1). These include vaborbactam, a $\beta$-lactamase inhibitor, tavaborole, a leucyl-tRNA synthetase inhibitor, and crisaborole, a phosphodiesterase-4 inhibitor. Several other borocycles acting as $\beta$-lactamase inhibitors were identified [16-19], and Imperio et al. reported cyclic boronic acid sugar analogues which could function as potential agents in boron neutron capture therapy [20]. Nevertheless, to the best of our knowledge, no cyclic boronates were investigated as iCP inhibitors until the present work.

\section{Methods}

\subsection{General chemistry methods}

Compounds 1, 2, 3, 4, 5, and 7 were purchased from Enamine Ltd, compounds 6, 8, 9, 10, 11, and 12 were purchased from Chemspace and all were used for biochemical screening as supplied. ${ }^{1} \mathrm{H}$ and ${ }^{13} \mathrm{C}$ NMR spectra were recorded on a Bruker Avance III $400 \mathrm{MHz}$ spectrometer at $295 \mathrm{~K}$. The chemical shifts $(\delta)$ are reported in parts per million (ppm) and are referenced to the deuterated solvent used. The coupling constants $(J)$ are given in $\mathrm{Hz}$, and the splitting patterns are designated as follows:

- $s$ : singlet;

- $d$ : doublet;

- $d d$ : double doublet;

- $t$ : triplet;

- $t d$ : triplet of doublets;

- $m$ : multiplet.

Analytical reversed-phase HPLC was performed on Thermo Scientific Dionex UltiMate 3000 UHPLC modular system, equipped with a photodiode array detector set to $254 \mathrm{~nm}$. An Acquity UPLC ${ }^{\circledR}$ BEH Shield RP18 Column $(2.1 \times 100 \mathrm{~mm} ; 1.7 \mu \mathrm{m})$ was used, thermostated at $40{ }^{\circ} \mathrm{C}$, and flow rate was set to $0.3 \mathrm{~mL} / \mathrm{min}$. Compound solutions

Table 1 FDA-approved drugs containing boronic acid moiety

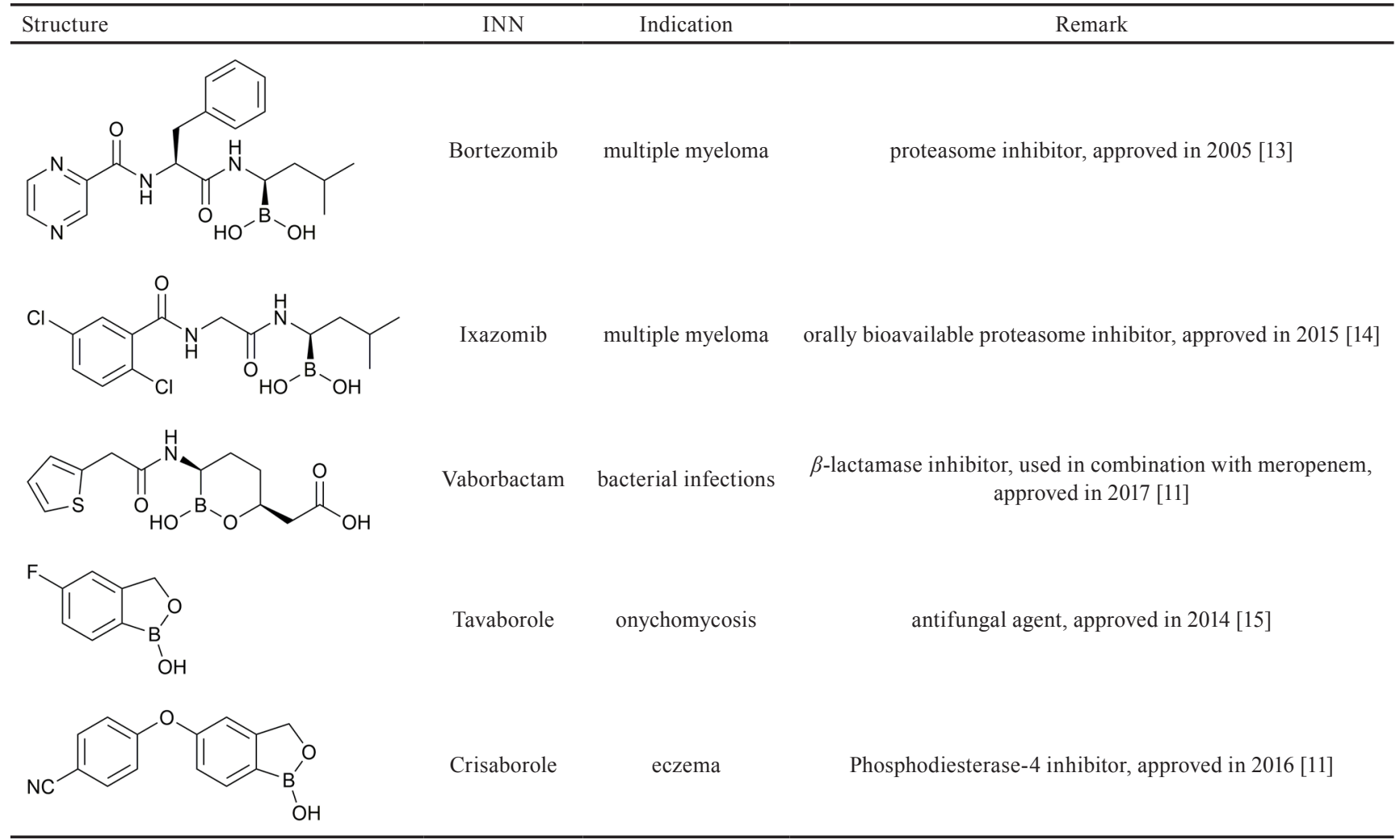


were prepared as $0.5 \mathrm{mM}$ in $\mathrm{MeCN}$ with $5 \% \mathrm{DMSO}, 1 \mu \mathrm{L}$ of which was injected. For the determination of stability, $0.5 \mathrm{mM}$ compound was incubated for $18 \mathrm{~h}$ in buffer $(50 \mathrm{mM}$ TRIS-Cl, 0.5 mM EDTA, pH 7.4, 2 \% DMSO). After the incubation, $1 \mu \mathrm{L}$ of this solution was injected. An eluent system of $\mathrm{A}\left(0.1 \%\right.$ TFA in $\left.\mathrm{H}_{2} \mathrm{O}\right)$ and $\mathrm{B}(\mathrm{MeCN})$ was used with gradient elution: $0-10 \mathrm{~min}, 5 \% \mathrm{~B} \rightarrow 80 \% \mathrm{~B}$; $10-12 \min , 80 \% \mathrm{~B} ; 12-12.5 \mathrm{~min}, 80 \% \mathrm{~B} \rightarrow 5 \% \mathrm{~B}$.

\section{2 ${ }^{1} \mathrm{H}$ NMR and HPLC analyses of compounds}

$N$-((2,2-difluorocyclopentyl)methyl)-1-hydroxy-1,3-dihydrobenzo[c][1,2]oxaborole-6-carboxamide (1): ${ }^{1} \mathrm{H}$ NMR $\left(400 \mathrm{MHz}, \mathrm{DMSO}-d_{6}\right) \delta 9.30(\mathrm{~s}, 1 \mathrm{H}, \mathrm{BO} \underline{\mathrm{H}}), 8.56(\mathrm{t}$, $J=5.6 \mathrm{~Hz}, 1 \mathrm{H}, \mathrm{NH}), 8.20$ (d, $J=0.9 \mathrm{~Hz}, 1 \mathrm{H}, \mathrm{Ar}-\underline{\mathrm{H}}), 7.91$ (dd, $J=8.0,1.7 \mathrm{~Hz}, 1 \mathrm{H}, \mathrm{Ar}-\underline{\mathrm{H}}), 7.49$ (d, $J=8.0 \mathrm{~Hz}, \mathrm{Ar}-\underline{\mathrm{H}}$ ), $5.04\left(\mathrm{~s}, 2 \mathrm{H}, \mathrm{CH}_{2}\right), 3.50-3.24\left(\mathrm{~m}, 2 \mathrm{H}, \mathrm{CH}_{2}\right.$, overlap with residual water peak), $2.23-1.43\left(\mathrm{~m}, 7 \mathrm{H}, 3 \times \mathrm{CH}_{2}\right.$, $\mathrm{CH}$ ); purity by HPLC: $91.0 \%$; stability in buffer: $99.2 \%$ after $18 \mathrm{~h}$.

2-Hydroxy- $N$-(1-hydroxy-3,4-dihydro-1 $H$-benzo[c][1,2] oxaborinin-7-yl)-2-methyl-4-phenylbutanamide

${ }^{1} \mathrm{H}$ NMR ( $400 \mathrm{MHz}, \mathrm{DMSO}-d_{6}$ ) $\delta 9.47$ (s, 1H, BOH $), 8.40$ (s, 1H, Ar- $\underline{\mathrm{H}}$ ), 7.96 (d, $J=2.3 \mathrm{~Hz}, 1 \mathrm{H}, \mathrm{Ar}-\underline{\mathrm{H}}), 7.67$ (dd, $J=8.2,2.3 \mathrm{~Hz}, 1 \mathrm{H}, \mathrm{Ar}-\underline{\mathrm{H}}), 7.29-7.23$ (m, 2H, $2 \times$ Ar- $\underline{\mathrm{H}})$, $7.20-7.12(\mathrm{~m}, J=8.3 \mathrm{~Hz}, 4 \mathrm{H}, 3 \times \mathrm{Ar}-\underline{\mathrm{H}}), 5.72(\mathrm{~s}, 1 \mathrm{H}), 4.05$ (t, $J=5.9 \mathrm{~Hz}, 2 \mathrm{H}, \mathrm{CH}_{2} \underline{\mathrm{C}}_{2} \mathrm{OB}$ ), 2.82 (t, $J=5.8 \mathrm{~Hz}, 2 \mathrm{H}$, $\mathrm{CH}_{2} \mathrm{CH}_{2} \mathrm{OB}$ ), $2.79-2.70$ (m, td, 1H, overlap), $2.48-2.37$ $(\mathrm{m}, \mathrm{td}, 1 \mathrm{H}$, overlap with residual water peak), $2.04(\mathrm{td}$, $J=13.0,4.7 \mathrm{~Hz}, 1 \mathrm{H}), 1.81(\mathrm{td}, J=13.0,4.6 \mathrm{~Hz}, 1 \mathrm{H}), 1.39$ ( $\mathrm{s}, 3 \mathrm{H}, \mathrm{CH}_{3}$ ); purity by HPLC: $97.0 \%$; stability in buffer: $99.8 \%$ after $18 \mathrm{~h}$.

\subsection{Residual activity determination}

The biochemical screening of compounds was performed at $100 \mu \mathrm{M}$ final concentrations in assay buffer $(0.01 \%$ $\mathrm{SDS}, 50 \mathrm{mM}$ Tris-HCl, $0.5 \mathrm{mM}$ EDTA, $\mathrm{pH}$ 7.4). To each compound, 0.2 nM human iCP (Boston Biochem, Inc., Cambridge, MA, USA) was added and incubated for $30 \mathrm{~min}$ at $37^{\circ} \mathrm{C}$. Afterwards, the reaction was initiated by the addition of Suc-LLVY-AMC (Bachem, Bubendorf, Switzerland) at $25 \mu \mathrm{M}$ final concentration. This substrate was used to monitor the residual activity of the $\beta 5 \mathrm{i}$ subunit of the iCP. The reaction progress was recorded on the BioTek Synergy HT microplate reader by monitoring fluorescence at $460 \mathrm{~nm}\left(\lambda_{e x}=360 \mathrm{~nm}\right)$ for $90 \mathrm{~min}$ at $37{ }^{\circ} \mathrm{C}$. The initial linear ranges were used to calculate the velocity and to determine the residual activity.

\subsection{Virtual screening}

Commercially available borocycles were collected from eMolecules [21] building blocks and screening compounds. LigPrep by Schrödinger [22] was used to generate 3D conformations, tautomeric and ionization states from SMILES codes at $\mathrm{pH}$ 6-8, while retaining specified chiralities. The X-ray structure deposited as PDB entry $6 \mathrm{E} 5 \mathrm{~B}$ [23] was used for the virtual screening. The binding site is defined by the $\mathrm{K}$ and $\mathrm{L}$ chains, so all other chains were removed, as well as the covalently bound ligand. Protein Preparation Wizard [24, 25] was used to add hydrogen atoms, protonate residues at $\mathrm{pH} 7$, refine the $\mathrm{H}$-bond network and to perform a restrained minimization. The receptor's grid box required for docking calculations was centered on the corresponding co-crystallized ligand. Covalent docking was performed with CovDock program of the Schrödinger suite [22]. The pose prediction mode [26] with default setup was applied. The top scored docking poses were visually inspected to select compounds for experimental testing.

\section{Results and discussion}

The compounds selected for virtual screening were cyclic boronic acids with 5- and 6-membered rings as shown in Fig. 1.

304 and 100 compounds with 5- and 6-membered ring, respectively, were collected (Table $\mathrm{S} 1$ and Table S2 in the Supplement). Their covalent docking to the Thrl residue of the $\beta 5$ i subunit of iCP resulted in various poses. Compounds that were oriented outward the binding site were not considered as potential hits. Several docked compounds adopted a binding mode resembling that of Ro19 (PDB: 5M2B), a non-peptidic $\beta 5$ i-selective inhibitor of human iCP [27]. These compounds oriented toward the Table S1 binding pocket whose different size in iCP and CP was proposed to be responsible for subtype selectivity [27]. Some other compounds adopted a position similar to that of peptid-like ligands that fit into the binding channel with main chain H-bonds and protrude into the subpockets by their sidechains. However, the docked cyclic boronic acids were unable to form the hydrogen bond pattern typical

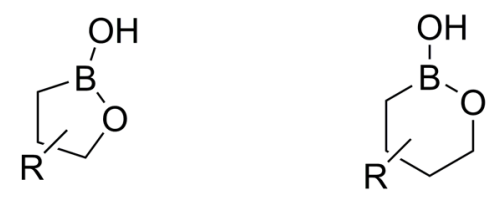

Fig. 1 General formula of the borocycles with 5- and 6-membered rings 
to peptide-like covalent ligands that are hydrogen bounded to Ser21 and Gly47 backbone amine and carbonyl, respectively. The binding modes proposed by covalent docking for compounds $\mathbf{1}$ and $\mathbf{7}$ are shown in Fig. 2.

Six compounds with 5-membered ring and another six compounds with 6-membered ring were selected for $\beta 5 \mathrm{i}$ inhibition assays. The selection was made by visual inspection taking into account docking scores and diversity of the selected compounds. The inhibitory activity was measured at $100 \mu \mathrm{M}$ concentration and the residual activities are shown in Table 2.
All compounds exhibit detectable inhibitory activity at $100 \mu \mathrm{M}$ concentration. The remaining enzyme activity was around $50 \%$ suggesting $\mathrm{IC}_{50}$ values in the $100 \mu \mathrm{M}$ range. The activities were fairly uniform for both the 5and 6-membered borocycles with no apparent effect of the substituent of the aromatic ring. Out of the 12 compounds, nine contain amide functional group as this moiety was highly represented in the screened library owing to synthetic reasons. However, direct interaction between the amide group and the protein was observed only for some of the compounds in the docked binding mode.
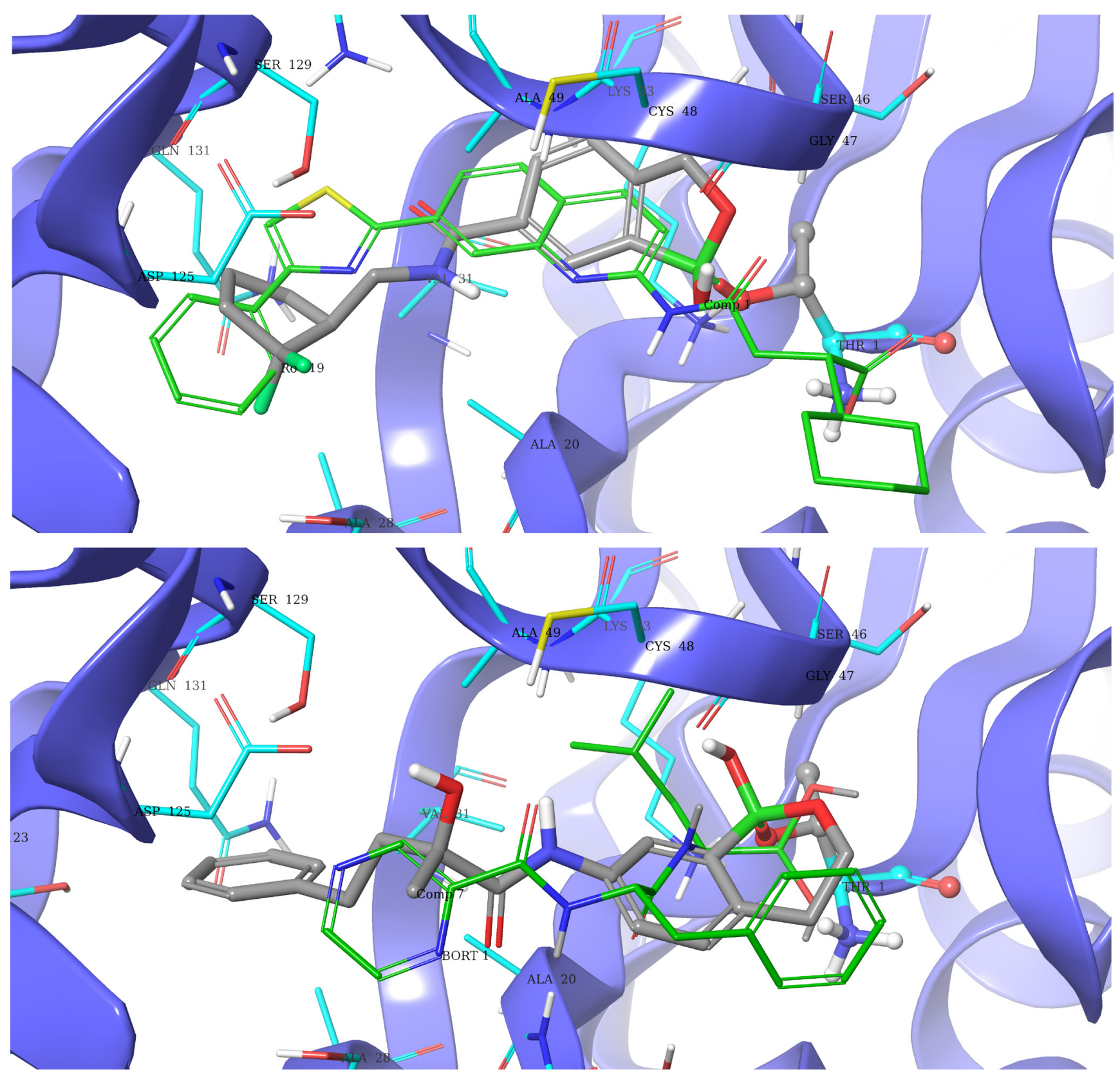

Fig. 2 Binding modes of compounds 1 (top) and 7 (bottom) as proposed by covalent docking. Cyclic boronic acid ligands are shown with grey carbon atoms in stick representation. The overlaid Ro19 (top) and bortezomib (bottom) ligands are shown with green carbon atoms in thin stick representation. Covalently labelled Thrl is shown in ball-and-stick representation. See text for the discussion of the binding modes. 
Table 2 Biochemical assay results for the virtual screening hits

\begin{tabular}{ll}
\hline Label Structure & $\begin{array}{l}\text { Residual activity (\%) } \\
\text { at } 100 \mu \mathrm{M} \text { compound }\end{array}$ \\
\hline
\end{tabular}

1<smiles>O=C(NCC1CCCC1(F)F)c1ccc2c(c1)B(O)OC2</smiles>

2<smiles>CC1OB(O)c2cc(CO)c(F)cc21</smiles><smiles>N#CC[C@@H]1CC[C@@H](NC(=O)c2ccc3c(c2)B(O)OC3)C1</smiles>

6<smiles>Cc1n[nH]c(CNC(=O)c2ccc3c(c2)COB3O)c1C</smiles>

7<smiles>CC(O)(CCc1ccccc1)C(=O)Nc1ccc2c(c1)B(O)OCC2</smiles>

8<smiles>CCOc1cc(CNc2ccc3c(c2)B(O)OCC3)ccc1OC</smiles>

9<smiles>O=C(Nc1ccc2c(c1)B(O)OCC2)C12CCN(CC1)CC2</smiles>
$53 \pm 17$<smiles>CC1(C)Cc2ccc(NC(=O)CNC(=O)N3CCCC3)cc2B(O)O1</smiles>

The inhibitory activities of compounds with substituents on the borocycle (compounds $\mathbf{2}, \mathbf{5}, \mathbf{1 0}$, and $\mathbf{1 1}$ ) did not show a clear trend either.

Compounds 1 and 7, which showed the strongest inhibition with residual activities values below $40 \%$ (Table 2) were further analysed by ${ }^{1} \mathrm{H}$ NMR and HPLC to confirm their uniformity. In addition, buffer stability assay was performed for these two borocycles in order to evaluate the aqueous stability of the oxaborole (in compound 1) and oxaborinin (in compound 7) moieties. In both cases, the $18 \mathrm{~h}$ treatment of compounds in the assay buffer did not chemically alter the compounds.

Although covalent inhibitors most often exhibit higher than micromolar affinity toward their target, the observation that the fairly diverse set of compounds with similar cyclic boronic acid warheads has similar activity suggests that reactivity is the primary determinant for inhibitory activity. Moreover, neither the reactivity nor the compound recognition by the protein was significantly affected by the substitution pattern. Assuming covalent inhibition, the modest activity of these compounds suggests that either the electrophilicities of the cyclic boronic acid moieties are low, or that these warheads are not placed in an optimal position with respect to the $\mathrm{OH}$ group of the catalytic Thr1 in $\beta 5$ i active site.

\section{Conclusions}

We investigated a set of cyclic boronic acids as inhibitors of the $\beta 5 \mathrm{i}$ subunit of the immunoproteasome. The biochemical evaluation of twelve compounds selected by virtual screening showed activities in the micromolar range. We believe that further work with borocycles as proteasome inhibitors is warranted. Evaluations of larger libraries of compound are needed to fully elucidate the potential of these structures as inhibitors of either $\mathrm{CP}$ or iCP.

\section{Acknowledgments}

The research was funded by the National Research Development and Innovation Office (grant number SNN_17 125496), Ph.D. scholarship from the Gedeon Richter's Talentum Foundation, and the Slovenian Research Agency (Grants N1-0068, J3-1745, and P1-0208).

\section{Abbreviations}

FDA: Food and Drug Administration

iCP: immunoproteasome

INN: International Nonproprietary Name 


\section{References}

[1] Ettari, R., Zappalà, M., Grasso, S., Musolino, C., Innao, V., Allegra, A. "Immunoproteasome-selective and non-selective inhibitors: A promising approach for the treatment of multiple myeloma", Pharmacology \& Therapeutics, 182, pp. 176-192, 2018. https://doi.org/10.1016/j.pharmthera.2017.09.001

[2] Kisselev, A. F., Groettrup, M. "Subunit specific inhibitors of proteasomes and their potential for immunomodulation", Current Opinion in Chemical Biology, 23, pp. 16-22, 2014. https://doi.org/10.1016/j.cbpa.2014.08.012

[3] Zerfas, B. L., Maresh, M. E., Trader, D. J. "The Immunoproteasome: An Emerging Target in Cancer and Autoimmune and Neurological Disorders", Journal of Medicinal Chemistry, 63(5), pp. 1841-1858, 2020.

https://doi.org/10.1021/acs.jmedchem.9b01226

[4] Thibaudeau, T. A., Smith, D. M. "A Practical Review of Proteasome Pharmacology", Pharmacological Reviews, 71(2), pp. 170-197, 2019. https://doi.org/10.1124/pr.117.015370

[5] Sherman, D. J., Li, J. "Proteasome Inhibitors: Harnessing Proteostasis to Combat Disease", Molecules, 25(3), Article Number: 671, 2020. https://doi.org/10.3390/molecules25030671

[6] Xi, J., Zhuang, R., Kong, L., He, R., Zhu, H., Zhang, J. "Immunoproteasome-selective inhibitors: An overview of recent developments as potential drugs for hematologic malignancies and autoimmune diseases", European Journal of Medicinal Chemistry, 182, Article Number: 111646, 2019.

https://doi.org/10.1016/j.ejmech.2019.111646

[7] Trippier, P. C., McGuigan, C. "Boronic acids in medicinal chemistry: Anticancer, antibacterial and antiviral applications", Medicinal Chemistry Communications, 1(3), pp. 183-198, 2010. https://doi.org/10.1039/c0md00119h

[8] Miyaura, N., Suzuki, A. "Palladium-Catalyzed Cross-Coupling Reactions of Organoboron Compounds", Chemical Reviews, 95(7), pp. 2457-2483, 1995. https://doi.org/10.1021/cr00039a007

[9] Lam, P. Y. S., Clark, C. G., Saubern, S., Adams, J., Winters, M. P., Chan, D. M. T., Combs, A. "New aryl/heteroaryl C-N bond cross-coupling reactions via arylboronic acid/cupric acetate arylation", Tetrahedron Letters, 39(19), pp. 2941-2944, 1998. https://doi.org/10.1016/S0040-4039(98)00504-8

[10] Petasis, N. A., Akritopoulou, I. "The boronic acid mannich reaction: A new method for the synthesis of geometrically pure allylamines", Tetrahedron Letters, 34(4), pp. 583-586, 1993. https://doi.org/10.1016/S0040-4039(00)61625-8

[11] Plescia, J., Moitessier, N. "Design and discovery of boronic acid drugs", European Journal of Medicinal Chemistry, 195, Article Number: 112270, 2020.

https://doi.org/10.1016/j.ejmech.2020.112270
[12] Fu, H., Fang, H., Sun, J., Wang, H., Liu, A., Sun, J., Wu, Z. "Boronic Acid-based Enzyme Inhibitors: A Review of Recent Progress", Current Medicinal Chemistry, 21(28), pp. 3271-3280, 2014. https://doi.org/10.2174/0929867321666140601200803

[13] Kane, R. C., Farrell, A. T., Sridhara, R., Pazdur, R. "United States Food and Drug Administration Approval Summary: Bortezomib for the Treatment of Progressive Multiple Myeloma after One Prior Therapy", Clinical Cancer Research, 12(10), pp. 2955-2960, 2006. https://doi.org/10.1158/1078-0432.CCR-06-0170

[14] Shirley, M. "Ixazomib: First Global Approval", Drugs, 76(3), pp. 405-411, 2016. https://doi.org/10.1007/s40265-016-0548-5

[15] Markham, A. "Tavaborole: First Global Approval", Drugs, 74(13), pp. 1555-1558, 2014. https://doi.org/10.1007/s40265-014-0276-7

[16] Hecker, S. J., Reddy, K. R., Lomovskaya, O., Griffith, D. C., Rubio-Aparicio, D., Nelson, K., Tsivkovski, R., Sun, D., Sabet, M., Tarazi, Z., Parkinson, J., Totrov, M., Boyer, S. H., Glinka, T. W., Pemberton, O. A., Chen, Y., Dudley, M. N. "Discovery of Cyclic Boronic Acid QPX7728, an Ultrabroad-Spectrum Inhibitor of Serine and Metallo- $\beta$-lactamases", Journal of Medicinal Chemistry, 63(14), pp. 7491-7507, 2020.

https://doi.org/10.1021/acs.jmedchem.9b01976

[17] Hecker, S. J., Reddy, K. R., Totrov, M., Hirst, G. C., Lomovskaya, O., Griffith, D. C., King, P., Tsivkovski, R., Sun, D., Sabet, M., Tarazi, Z., Clifton, M. C., Atkins, K., Raymond, A., Potts, K. T., Abendroth, J., Boyer, S. H., Loutit, J. S. Morgan, E. E., Durso, S., Dudley, M. N. "Discovery of a Cyclic Boronic Acid $\beta$-Lactamase Inhibitor (RPX7009) with Utility vs Class A Serine Carbapenemases", Journal of Medicinal Chemistry, 58(9), pp. 3682-3692, 2015.

https://doi.org/10.1021/acs.jmedchem.5b00127

[18] Tooke, C. L., Hinchliffe, P., Krajnc, A., Mulholland, A. J., Brem, J., Schofield, C. J., Spencer, J. "Cyclic boronates as versatile scaffolds for KPC-2 $\beta$-lactamase inhibition", RSC Medicinal Chemistry, 11(4), pp. 491-496, 2020.

https://doi.org/10.1039/c9md00557a

[19] Cahill, S. T., Cain, R., Wang, D. Y., Lohans, C. T., Wareham, D. W., Oswin, H. P., Mohammed, J., Spencer, J., Fishwick, C. W. G., McDonough, M. A., Schofield, C. J., Brem, J. "Cyclic Boronates Inhibit All Classes of $\beta$-Lactamases", Antimicrobial Agents and Chemotherapy, 61(4), Article Number: e02260-16, 2017. https://doi.org/10.1128/AAC.02260-16

[20] Imperio, D., Del Grosso, E., Fallarini, S., Lombardi, G., Panza, L. "Anomeric sugar boronic acid analogues as potential agents for boron neutron capture therapy", Beilstein Journal of Organic Chemisty, 15, pp. 1355-1359, 2019. https://doi.org/10.3762/bjoc.15.135 
[21] eMolecules "eMolecules", [online]. Available at: https://www. emolecules.com [Accessed: 12 December 2019]

[22] Schrödinger LLC "Ligprep, (Schrödinger Release 2018-4)", [computer program] Available at: https://www.schrodinger.com [Accessed: 17 January 2020]

[23] Ladi, E., Everett, C., Stivala, C. E., Daniels, B. E., Durk, M. R., Harris, S. F., Huestis, M. P., Purkey, H. E., Staben, S. T., Augustin, M., Blaesse, M., Steinbacher, S., Eidenschenk, C., Pappu, R., Siu, M. "Design and Evaluation of Highly Selective Human Immunoproteasome Inhibitors Reveal a Compensatory Process that Preserves Immune Cell Viability", Journal of Medicinal Chemistry, 62(15), pp. 7032-7041, 2019. https://doi.org/10.1021/acs.jmedchem.9b00509

[24] Schrödinger LLC "Protein Preparation Wizard, (Schrödinger Release 2018-4)", [computer program] Available at: https://www. schrodinger.com [Accessed: 17 January 2020]
[25] Madhavi Sastry, G., Adzhigirey, M., Day, T., Annabhimoju, R., Sherman, W. "Protein and ligand preparation: parameters, protocols, and influence on virtual screening enrichments", Journal of Computer-Aided Molecular Design, 27(3), pp. 221-234, 2013. https://doi.org/10.1007/s10822-013-9644-8

[26] Zhu, K., Borrelli, K. W., Greenwood, J. R., Day, T., Abel, R., Farid, R. S., Harder, E. "Docking Covalent Inhibitors: A Parameter Free Approach To Pose Prediction and Scoring", Journal of Chemical Information and Modeling, 54(7), pp. 1932-1940, 2014. https://doi.org/10.1021/ci500118s

[27] Cui, H., Baur, R., Le Chapelain, C., Dubiella, C., Heinemeyer, W., Huber, E. M., Groll, M. "Structural Elucidation of a Nonpeptidic Inhibitor Specific for the Human Immunoproteasome", ChemBioChem, 18(6), pp. 523-526, 2017. https://doi.org/10.1002/cbic.201700021 